\title{
RELAP5-3D Code Includes Athena Features and Models
}

\section{International Conference on Nuclear Engineering - ICONE 14-89217}

\author{
Richard A. Riemke \\ Cliff B. Davis \\ Richard R. Schultz
}

\author{
July 2006
}

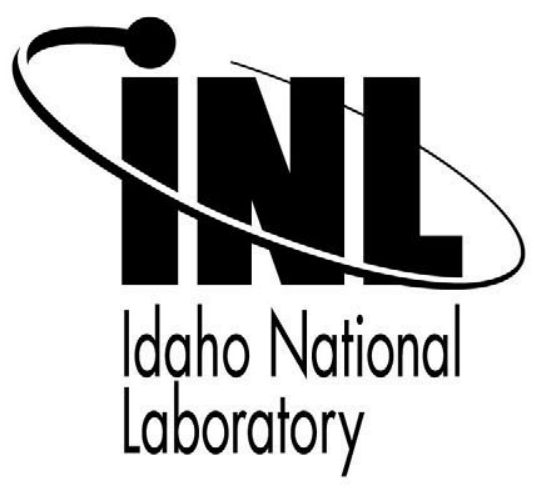

This is a preprint of a paper intended for publication in a journal or proceedings. Since changes may not be made before publication, this preprint should not be cited or reproduced without permission of the author. This document was prepared as an account of work sponsored by an agency of the United States Government. Neither the United States Government nor any agency thereof, or any of their employees, makes any warranty, expressed or implied, or assumes any legal liability or responsibility for any third party's use, or the results of such use, of any information, apparatus, product or process disclosed in this report, or represents that its use by such third party would not infringe privately owned rights. The views expressed in this paper are not necessarily those of the United States Government or the sponsoring agency. 
ICONE14-89217

\title{
RELAP5-3D CODE INCLUDES ATHENA FEATURES AND MODELS
}

\author{
Richard A. Riemke \\ Idaho National Laboratory, Idaho Falls, Idaho \\ 83415-3890, USA \\ Phone: 208-526-0697 \\ Fax: 208-526-0528 \\ Email: Richard.Riemke@inl.gov
}

\author{
Cliff B. Davis \\ Idaho National Laboratory, Idaho Falls, Idaho \\ 83415-3890, USA \\ Phone: 208-526-9470 \\ Fax: 208-526-0528 \\ Email: Cliff.Davis@inl.gov
}

\author{
Richard R. Schultz \\ Idaho National Laboratory, Idaho Falls, Idaho \\ 83415-3890, USA \\ Phone: 208-526-9508 \\ Fax: 208-526-0528 \\ Email: Richard.Schultz@inl.gov
}

\section{ABSTRACT}

Version 2.3 of the RELAP5-3D computer program includes all features and models previously available only in the ATHENA version of the code. These include the addition of new working fluids (i.e., ammonia, blood, carbon dioxide, glycerol, helium, hydrogen, lead-bismuth, lithium, lithium-lead, nitrogen, potassium, sodium, and sodium-potassium) and a magnetohydrodynamic model that expands the capability of the code to model many more thermal-hydraulic systems. In addition to the new working fluids along with the standard working fluid water, one or more noncondensable gases (e.g., air, argon, carbon dioxide, carbon monoxide, helium, hydrogen, krypton, nitrogen, oxygen, sf6, xenon) can be specified as part of the vapor/gas phase of the working fluid. These noncondensable gases were in previous versions of RELAP53D. Recently four molten salts have been added as working fluids to RELAP5-3D Version 2.4, which has had limited release. These molten salts will be in RELAP5-3D Version 2.5, which will have a general release like RELAP5-3D Version 2.3. Applications that use these new features and models are discussed in this paper.

\section{INTRODUCTION}

The RELAP5 series of codes has been developed at the Idaho National Laboratory for over 25 years under sponsorship of the U. S. Department of Energy, the U. S. Nuclear Regulatory Commission, members of the International Code Assessment and Applications Program, members of the Code Applications and Maintenance Program, and members of the International RELAP5 Users Group. Specific world-wide applications of the code have included simulations of transients of light water reactor systems such as loss of coolant, anticipated transients without scram, and operational transients such as loss of feedwater, loss of offsite power, station blackout, and turbine trip. RELAP5-3D (Ref. 1), the latest in the series of RELAP5 codes, extends the applicability of earlier versions to include an integrated multidimensional thermalhydraulic/neutronic capability. In addition to calculating the behavior of a reactor coolant system during a transient, it can be used for simulation of a wide variety of hydraulic and thermal transients in both nuclear and nonnuclear systems involving mixtures of vapor, liquid, noncondensable gases, and nonvolatile solute. The 3D capability in RELAP5-3D includes 3D hydrodynamics and 3D neutron kinetics [the 3D neutronics is based on the NESTLE code (Ref. 2)]. RELAP5-3D was 
recently modified to include all the ATHENA (Ref. 3) features and models that were previously only available in the ATHENA configuration. The ATHENA features and models are currently used primarily in Generation IV reactor applications, space reactor applications, and nuclear fusion applications.

RELAP5-3D is also used in a SCDAP/RELAP5-3D (Ref. 4) configuration that is designed to calculate for severe accident situations the overall reactor coolant system thermal-hydraulic response, core damage progression, and reactor vessel heatup and damage. RELAP5-3D (also true of SCDAP/RELAP5-3D) is also used in an integrated code system configuration consisting of RELAP5-3D and other codes such as FLUENT, CFX, and CONTAIN. The coupling of the codes in this configuration is coordinated using an executive program (Ref. 5) in concert with the Parallel Virtual Machine (PVM) message passing software. The coupling can be done explicitly or semiimplicitly. For example, the FLUENT/RELAP5-3D (Ref. 6) coupling configuration is designed to perform detailed 3D analyses using FLUENT's capability while the boundary conditions required by the FLUENT calculation are provided by the balance-of-system model created using RELAP5-3D. The FLUENT/RELAP5-3D coupling configuration is currently used primarily in Generation IV reactor applications. RELAP5-3D is also used for the thermal-hydraulic module in the real-time nuclear plant simulation code RELAP5-R/T (Refs. 7, 8, 9), which is used in training simulators at nuclear power plants around the world. There is also a visualization system for the various RELAP5-3D configurations, which is called the RELAP5-3D Graphical User Interface (RGUI) (Ref. 10).

This paper discusses Version 2.3 of the RELAP5-3D computer program that now includes all features and models that were previously available in the ATHENA configuration version of the code. They are new working fluids and a magnetohydrodynamic model. This paper also discusses four molten salts that have been added as working fluids to RELAP5-3D Version 2.4, which has had limited release. These molten salts will be in RELAP5-3D Version 2.5, which will have a general release like RELAP5-3D Version 2.3. Applications that use these new features and models will be discussed in this paper.

\section{WORKING FLUIDS}

In the 1980's, various working fluids began to be added to the ATHENA configuration (Ref. 11, 12) of the RELAP5 code. When RELAP5-3D began in the 1990's to extend the capability of RELAP5, the ATHENA configuration (with its various working fluids) was continued and enhanced in the RELAP53D code.

The working fluids that were previously available in RELAP5-3D and are still available to RELAP5-3D Version 2.3 are as follows: light water (specified as h2o), heavy water (d2o),
1984 light water (h2on), and 1995 light water (h2095). The additional working fluids now available to RELAP5-3D Version 2.3 that were previously available only in the ATHENA configuration are as follows: ammonia (nh3), blood (blood), carbon dioxide (co2), glycerol (glycerol), helium (he), hydrogen (h2), lead-bismuth (bipb), lithium (li), lithium-lead (lipb), nitrogen (n2), potassium (k), sodium (na), and sodiumpotassium (nak).

Four molten salts $\left[\mathrm{LiF}-\mathrm{BeF}_{2}(0.66-0.34)(\mathrm{ms} 1), \mathrm{NaBF}_{4}{ }^{-}\right.$ $\mathrm{NaF}(0.92-0.08)(\mathrm{ms} 2)$, LiF-NaF-KF $(0.465-0.115-0.42)$ (ms3), and $\left.\mathrm{NaF}_{-} \mathrm{ZrF}_{4}(0.50-0.50)(\mathrm{ms} 4)\right]$ have recently been added as working fluids to RELAP5-3D Version 2.4.

The basic properties for light water (specified as h2o) are calculated from default thermodynamic tables (Ref. 13, 14, 15) that tabulate saturation properties as a function of temperature, saturation properties as a function of pressure, and single-phase properties as a function of pressure and temperature. These tables are based on the 1967 ASME Steam Tables (Ref. 13), which are calculated using the 1967 International Formulation Committee (IFC) Formulation for Industrial Use and is known as IFC-67. The properties and derivatives in the tables are saturation pressure, saturation temperature, specific volume, specific internal energy, and three derivatives (isobaric thermal expansion coefficient, isothermal compressibility, and specific heat at constant pressure). The transport properties (viscosity, thermal conductivity, and surface tension) are based on correlations from the 1967 ASME Steam Tables (Ref. 13) and Schmidt (Ref. 16).

The basic properties for heavy water (specified as $\mathrm{d} 2 \mathrm{o}$ ) are calculated from optional (activated by the user in the input deck) thermodynamic tables (Ref. 17, 18, 19) that tabulate saturation properties as a function of temperature, saturation properties as a function of pressure, and single-phase properties as a function of pressure and temperature. These tables are based on the formulation from the Atomic Energy of Canada Limited (AECL) (Ref. 18) and the WASP program (Ref. 19) from the National Aeronautics and Space Administration (NASA). The properties and derivatives in the tables are saturation pressure, saturation temperature, specific volume, specific internal energy, and three derivatives (isobaric thermal expansion coefficient, isothermal compressibility, and specific heat at constant pressure). The transport properties (viscosity, thermal conductivity, and surface tension) are based on correlations from FLOWTRAN (Ref. 20) and TRAC (Ref. 21).

The basic properties for 1984 light water (specified as h2on) are calculated from optional (activated by the user in the input deck) thermodynamic tables (Ref. 22) that tabulate saturation properties as a function of temperature, saturation properties as a function of pressure, and single-phase properties as a function of pressure and specific internal energy. These tables are based on the 1984 U. S. National Bureau of 
Standards and the National Research Council of Canada (NBS/NRC) Steam Tables (Ref. 22). The properties and derivatives in the tables are saturation pressure, saturation temperature, specific volume, temperature, three derivatives (isobaric thermal expansion coefficient, isothermal compressibility, and specific heat at constant pressure), and transport properties (viscosity, thermal conductivity, and surface tension). The transport properties are based on correlations from the National Research Council of Canada (NBS/NRC) Steam Tables (Ref. 22).

The basic properties for 1995 light water (specified as h2o95) are calculated from optional (activated by the user in the input deck) thermodynamic tables (Ref. 23) that tabulate saturation properties as a function of temperature, saturation properties as a function of pressure, and single-phase properties as a function of pressure and temperature. These tables are based on the 1995 Steam Tables from the International Association for the Properties of Water and Steam (IAPWS) (Ref. 23); it is known as IAPWS-95. IAPWS also released an industrial formation in 1997 (known as IAPWS-97), which is not as accurate, but more efficient than the 1995 formulation. Since the tables in RELAP5-3D are only built once (during installation), the code uses IAPWS-95 because it is more accurate. The properties and derivatives in the tables are saturation pressure, saturation temperature, specific volume, specific internal energy, and three derivatives (isobaric thermal expansion coefficient, isothermal compressibility, and specific heat at constant pressure). The transport properties (viscosity, thermal conductivity, and surface tension) use tables based on correlations from the IAPWS-95 Steam Tables (Ref 23).

The basic properties for ammonia (specified as nh3) are calculated from optional (activated by the user in the input deck) thermodynamic tables (Ref. 24, 25, 26, 27) that tabulate saturation properties as a function of temperature, saturation properties as a function of pressure, and single-phase properties as a function of pressure and temperature. These tables are based on the formulation from Reynolds (Ref. 26) and were found to be in reasonable agreement with data in Vargaftik (Ref. 27). The properties and derivatives in the tables are saturation pressure, saturation temperature, specific volume, specific internal energy, and three derivatives (isobaric thermal expansion coefficient, isothermal compressibility, and specific heat at constant pressure). The transport properties are from formulations based on least square fits to data from Vargaftik (Ref. 27) and the Handbook of Chemistry and Physics (Ref. 28). The date of Reference 28 is 1973 , which is the actual date of handbook that was used in this work (References 26 and 27 are also dated in the 1970's). More recent editions of these references could be used to improve the properties.

The basic properties for blood (specified as blood) are calculated from optional (activated by the user in the input deck) thermodynamic tables (Ref. 29, 30, 31) that tabulate saturation properties as a function of temperature, saturation properties as a function of pressure, and single-phase properties as a function of pressure and temperature. These tables are based on the formulation from Daubert and Danner (Ref. 30) as well as Cooney (Ref. 31). The properties and derivatives in the tables are saturation pressure, saturation temperature, specific volume, specific internal energy, and three derivatives (isobaric thermal expansion coefficient, isothermal compressibility, and specific heat at constant pressure). The transport properties (viscosity, thermal conductivity, and surface tension) are from formulations based on least square fits to data from Daubert and Danner (Ref. 30) as well as Cooney (Ref. 31).

The basic properties for carbon dioxide (specified as co2) are calculated from optional (activated by the user in the input deck) thermodynamic tables (Ref. 32, 33) that tabulate saturation properties as a function of temperature, saturation properties as a function of pressure, and single-phase properties as a function of pressure and temperature. These tables are based on the formulation from National Institute of Standards and Technology (NIST) (Ref. 33). The properties and derivatives in the tables are saturation pressure, saturation temperature, specific volume, specific internal energy, and three derivatives (isobaric thermal expansion coefficient, isothermal compressibility, and specific heat at constant pressure). The transport properties (viscosity, thermal conductivity, and surface tension) are based on tables and correlations from NIST (Ref. 33), Hejzlar (Ref. 34), Dostal (Ref. 35), Vesovic et al. (Ref. 36), and Daubert et al. (Ref. 37).

The basic properties for glycerol (specified as glycerol) are calculated from optional (activated by the user in the input deck) thermodynamic tables (Ref. 29, 30) that tabulate saturation properties as a function of temperature, saturation properties as a function of pressure, and single-phase properties as a function of pressure and temperature. These tables are based on the formulation from Daubert and Danner (Ref. 30). The properties and derivatives in the tables are saturation pressure, saturation temperature, specific volume, specific internal energy, and three derivatives (isobaric thermal expansion coefficient, isothermal compressibility, and specific heat at constant pressure). The transport properties (viscosity, thermal conductivity, and surface tension) are from formulations based on least square fits to data from Daubert and Danner (Ref. 30).

The basic properties for helium (specified as he) are calculated from optional (activated by the user in the input deck) thermodynamic tables (Ref. 24, 26, 27, 38, 39) that tabulate saturation properties as a function of temperature, saturation properties as a function of pressure, and single-phase properties as a function of pressure and temperature. These tables are based on the formulations and least square fits to data from Reynolds (Ref. 26) and Vargaftik (Ref. 27). The properties and derivatives in the tables are saturation pressure, 
saturation temperature, specific volume, specific internal energy, and three derivatives (isobaric thermal expansion coefficient, isothermal compressibility, and specific heat at constant pressure). The transport properties (viscosity, thermal conductivity, and surface tension) are from formulations based on least square fits to data from Vargaftik (Ref. 27) and the Handbook of Chemistry and Physics (Ref. 28).

The basic properties for hydrogen (specified as h2) are calculated from optional (activated by the user in the input deck) thermodynamic tables (Ref. 24, 26, 27) that tabulate saturation properties as a function of temperature, saturation properties as a function of pressure, and single-phase properties as a function of pressure and temperature. These tables are based on the formulations and least square fits to data from Reynolds (Ref. 26) and Vargaftik (Ref. 27). The properties and derivatives in the tables are saturation pressure, saturation temperature, specific volume, specific internal energy, and three derivatives (isobaric thermal expansion coefficient, isothermal compressibility, and specific heat at constant pressure). The transport properties (viscosity, thermal conductivity, and surface tension) are from formulations based on least square fits to data from Vargaftik (Ref. 27) and the Handbook of Chemistry and Physics (Ref. 28).

The basic properties for lead-bismuth (specified as bipb) are calculated from optional (activated by the user in the input deck) thermodynamic tables (Ref. 40, 41, 42, 43, 44, 45, 46) that tabulate saturation properties as a function of temperature, saturation properties as a function of pressure, and single-phase properties as a function of pressure and temperature. These tables are based on Young's soft sphere model formulation (Ref. 42) and the Clausius-Clapeyron formulation. The formulations used were based on least square fits to data from Hultgren et al. (Ref. 44), Kutateladze et al. (Ref. 45), and Nesmeyanov (Ref. 46). The properties and derivatives in the tables are saturation pressure, saturation temperature, specific volume, specific internal energy, and three derivatives (isobaric thermal expansion coefficient, isothermal compressibility, and specific heat at constant pressure). The transport properties (viscosity, thermal conductivity, and surface tension) are from formulations based on least square fits to data from Touloukian et al. (Ref. 47) and Lyon (Ref. 48).

The basic properties for lithium (specified as li) are calculated from optional (activated by the user in the input deck) thermodynamic tables (Ref. 24, 26, 27, 39, 42, 43, 49, 50) that tabulate saturation properties as a function of temperature, saturation properties as a function of pressure, and single-phase properties as a function of pressure and temperature. These tables are based on Young's soft sphere model formulation (Ref. 42) and Reynolds' formulation (Ref. 26). The formulations used were based on fits to data from Young (Ref. 42), Blink (Ref. 50), and Vargaftik (Ref. 27). The properties and derivatives in the tables are saturation pressure, saturation temperature, specific volume, specific internal energy, and three derivatives (isobaric thermal expansion coefficient, isothermal compressibility, and specific heat at constant pressure). The transport properties (viscosity, thermal conductivity, and surface tension) are from formulations and least square fits to data from Vargaftik (Ref. 27), Maroni et al. (Ref. 51) and Smith et al. (Ref. 52).

The basic properties for lithium-lead (specified as lipb) are calculated from optional (activated by the user in the input deck) thermodynamic tables (Ref. 24, 42, 46, 50, 53) that tabulate saturation properties as a function of temperature, saturation properties as a function of pressure, and single-phase properties as a function of pressure and temperature. These tables are based on Young's soft sphere model formulation. The formulation used was based on fits to data from Young (Ref. 42), Blink (Ref. 50), and Nesmeyanov (Ref. 46). The properties and derivatives in the tables are saturation pressure, saturation temperature, specific volume, specific internal energy, and three derivatives (isobaric thermal expansion coefficient, isothermal compressibility, and specific heat at constant pressure). The transport properties (viscosity, thermal conductivity, and surface tension) are from formulations and least square fits to data from Vargaftik (Ref. 27) and the Handbook of Chemistry and Physics (Ref. 28).

The basic properties for nitrogen (specified as n2) are calculated from optional (activated by the user in the input deck) thermodynamic tables (Ref. 24, 26, 27, 38, 39, 53, 54) that tabulate saturation properties as a function of temperature, saturation properties as a function of pressure, and single-phase properties as a function of pressure and temperature. These tables are based on the formulations and least square fits to data from Reynolds (Ref. 26), Vargaftik (Ref. 27), and Angus et al. (Ref. 54). The properties and derivatives in the tables are saturation pressure, saturation temperature, specific volume, specific internal energy, and three derivatives (isobaric thermal expansion coefficient, isothermal compressibility, and specific heat at constant pressure). The transport properties (viscosity, thermal conductivity, and surface tension) are from formulations based on least square fits to data from Vargaftik (Ref. 27) and the National Bureau of Standards (Ref. 55).

The basic properties for potassium (specified as $\mathrm{k}$ ) are calculated from optional (activated by the user in the input deck) thermodynamic tables (Ref. 24, 26, 27, 42, 49, 56) that tabulate saturation properties as a function of temperature, saturation properties as a function of pressure, and single-phase properties as a function of pressure and temperature. These tables are based on Young's soft sphere model formulation (Ref. 42, 56) and Reynolds' formulation (Ref. 26). The formulations used were based on fits to data from Young (Ref. 42, 56) and Vargaftik (Ref. 27). The properties and derivatives in the tables are saturation pressure, saturation temperature, specific volume, specific internal energy, and three derivatives (isobaric thermal 
expansion coefficient, isothermal compressibility, and specific heat at constant pressure). The transport properties (viscosity, thermal conductivity, and surface tension) are from formulations and least square fits to data from Vargaftik (Ref. 27) and the Handbook of Chemistry and Physics (Ref. 28).

The basic properties for sodium (specified as na) are calculated from optional (activated by the user in the input deck) thermodynamic tables (Ref. 24, 26, 27, 38, 42, 57) that tabulate saturation properties as a function of temperature, saturation properties as a function of pressure, and single-phase properties as a function of pressure and temperature. These tables are based on Young's soft sphere model formulation (Ref. $42,57)$ and Reynolds' formulation (Ref. 26). The formulations used were based on fits to data from Young (Ref. 42, 57) and Vargaftik (Ref. 27). The properties and derivatives in the tables are saturation pressure, saturation temperature, specific volume, specific internal energy, and three derivatives (isobaric thermal expansion coefficient, isothermal compressibility, and specific heat at constant pressure). The transport properties (viscosity, thermal conductivity, and surface tension) are from formulations from Gierszewski et al. (Ref. 58) and least square fits to data from Vargaftik (Ref. 27).

The basic properties for sodium-potassium (specified as nak) are calculated from optional (activated by the user in the input deck) thermodynamic tables (Ref. 24, 26, 27, 38, 42, 56, $57,59)$ that tabulate saturation properties as a function of temperature, saturation properties as a function of pressure, and single-phase properties as a function of pressure and temperature. These tables are based on Young's soft sphere model formulation (Ref. 42) and Reynolds' formulation (Ref. 26). The formulations used were based on fits to data from Young (Ref. 42, 56, 57) and Vargaftik (Ref. 27). The properties and derivatives in the tables are saturation pressure, saturation temperature, specific volume, specific internal energy, and three derivatives (isobaric thermal expansion coefficient, isothermal compressibility, and specific heat at constant pressure). The transport properties (viscosity, thermal conductivity, and surface tension) are from formulations from Gierszewski et al. (Ref. 58) and least square fits to data from Vargaftik (Ref. 27) and Handbook of Physics and Chemistry (Ref. 28).

The basic properties for molten salt 1 (specified as ms1), molten salt 2 (specified as ms2), molten salt 3 (specified as ms3), and molten salt 4 (specified as ms4) are calculated from optional (activated by the user in the input deck) thermodynamic tables (Ref. 60, 61, 62, 63, 64, 65, 66) that tabulate saturation properties as a function of temperature, saturation properties as a function of pressure, and single-phase properties as a function of pressure and temperature. The four molten salts are $\mathrm{LiF}_{-\mathrm{BeF}_{2}}(0.66-0.34)(\mathrm{ms} 1), \mathrm{NaBF}_{4}-\mathrm{NaF}$ $(0.92-0.08)$ (ms2), LiF-NaF-KF $(0.465-0.115-0.42)(\mathrm{ms} 3)$, and $\mathrm{NaF}-\mathrm{ZrF}_{4}(0.50-0.50)(\mathrm{ms} 4)$, where the mole fraction of each component is given in parentheses. Molten salts ms1 and ms3 are generally referred to as Flibe and Flinak, respectively. These tables are based on a simplified equation of state, which is similar to the one used by Sabharwall et al. (Ref. 61) in an older version of ATHENA, and it was extended to higher pressures and temperatures for RELAP5-3D. The simplified equation of state is based on formulations from Powers et al. (Ref. 62), Cantor et al. (Ref. 63), Cantor (Ref. 64), Chase (Ref. 65), and Knacke et al. (Ref. 66). The properties and derivatives in the tables are saturation pressure, saturation temperature, specific volume, specific internal energy, three derivatives (isobaric thermal expansion coefficient, isothermal compressibility, and specific heat at constant pressure), and transport properties (viscosity, thermal conductivity, and surface tension). The transport properties are from formulations from Powers et al. (Ref. 62); Cantor et al. (Ref. 63); Cantor (Ref. 64); Bird, Stewart, and Lightfoot (Ref. 67); and Williams (Ref. $68)$.

\section{MAGNETOHYDRODYNAMIC MODEL}

The magnetohydrodynamic (MHD) effect, occurring when a fluid of high electrical conductivity moves through a magnetic field, is a common phenomenon in fusion reactor systems. A liquid metal flowing through a duct enveloped in a magnetic field experiences induced electromotive forces due to the qv $\mathrm{x}$ B forces acting upon the electrons in the conduction band, giving rise to electric currents in the liquid $(\mathrm{q}=$ electric charge, $\mathrm{v}=$ liquid velocity, $\mathrm{B}=$ magnetic force). Because of this energy conversion, there is an effective energy loss from the fluid flow. The RELAP5-3D model modifies the viscous energy loss coefficient (i.e., the friction loss coefficient) to account for this loss. Application of this model in RELAP5-3D is limited to pipe/annulus/pressurizer components that contain the working fluids lithium, lithium-lead, or sodium-potassium as subcooled liquid.

The model used to calculate the MHD effect in RELAP53D was developed at the Idaho National Laboratory (Ref. 69, 70,71 ), and it is based on the work from the University of California at Los Angeles and the Argonne National Laboratory. The model allows calculation of the pressure gradient resulting from the MHD effect. The model allows a circular duct and a rectangular duct. The model allows a uniform (constant nonfringe volume) magnetic field and a non-uniform (spatially varying fringe volume) magnetic field. A fringe volume is a volume at the edge of the magnetic field, where the field is nonuniform. The magnetic field is assumed perpendicular to the duct. The dimensionless Hartman number and the wall conduction ratio are used in the model.

\section{APPLICATIONS}

The fluids helium and nitrogen in the code have been recently used in the scoping transient analysis of the very high temperature reactor (VHTR) concept (Ref. 72). Low and high 
pressure loss of forced convection cooling transients were simulated.

The fluid helium in the code has been recently been used to analyze the helium gas-cooled fast reactor (GFR) concept (Ref. 73). The analysis was done to examine the potential for laminarization in the GFR design.

The fluid carbon dioxide in the code has been recently been used to support the development of a supercritical carbon dioxide cycle in the GFR concept (Ref. 74). One of the applications has been in the verification of the new compressor model in RELAP5-3D (Ref. 75).

The fluid lead-bismuth in the code has been recently used in the design and analysis of lead-bismuth cooled reactors (Ref. 41). The code was used in the design of corrosion experiments at the INL.

Various fluids and the magnetohydrodynamic model in the code have been used to analyze fusion loss-of-cooling accidents (Ref. 76). The code was used in the International Thermonuclear Experimental Reactor (ITER) international fusion design study.

\section{CONCLUSIONS}

This paper has discussed Version 2.3 of the RELAP5-3D computer program that now includes all features and models that were previously available in the ATHENA configuration version of the code. They are new working fluids and a magnetohydrodynamic model. This paper also discussed four molten salts that have been added as working fluids to RELAP5-3D Version 2.4, which has had limited release. These molten salts will be in RELAP5-3D Version 2.5, which will have a general release like RELAP5-3D Version 2.3. Applications that use these new features and models were discussed in this paper.

\section{ACKNOWLEDGMENTS}

This work was funded through the DOE under DOE/NE Idaho Operations Office Contract No. DE-AC07-05ID14517.

\section{REFERENCES}

1. The RELAP5-3D Code Development Team, 2005, "RELAP5-3D Code Manual," INEEL-EXT-98-00834, Revision 2.3, April, http://www.inel.gov/relap5/r5manuals.htm.

2. Turinsky, P., et al., 1994, "NESTLE: A Few-Group Neutron Diffusion Equation Solver Utilizing the Nodal Expansion Method for Eigenvalue, Adjoint, Fixed-
Source Steady State and Transient Problems," EGGNRE-11406, June.

3. Johnsen, G., C. Davis, and P. Bayless, 2004, ATHENA-3D for Generation IV Reactor Analysis, BE2004, ANS Winter Meeting, Washington D.C., November 14-18, http://www.inel.gov/relap5/athena/athena.htm.

4. The SCDAP/RELAP5-3D Development Team, 2003, "SCDAP/RELAP5-3D Code Manual," INEEL-EXT02-00589, Revision 2.2, October, http://www.inel.gov/relap5/scdap/scdap.htm.

5. Weaver, W., E. Tomlinson, and D. Aumiller, 2001, “A PVM Executive Program for Use with RELAP5-3D," 2001 RELAP5 International Users Seminar, Sun Valley, ID, USA, September 5-7, http://www.inel.gov/relap5/rius/sunvalley/weaver.pdf.

6. Schultz, R. and W. Weaver, 2003, "Using the RELAP5-3D Advanced Systems Analysis Code with Commercial and Advanced CFD Software," ICONE$11,11^{\text {th }}$ International Conference on Nuclear Engineering, Tokyo, Japan, April 20-23.

7. Williams, K., 2001, "Full-Scope Simulators Running Real-time RELAP5-R/T,” 2001 RELAP5 International Users Seminar, Sun Valley, ID, USA, September 5-7, http://www.inel.gov/relap5/rius/sunvalley/williams.pdf.

8. Hiltbrand, D. and K. Williams, 2001, "Utilization of a RELAP5 RCS and Secondary Plant Model in a Nuclear Power Plant Training Simulator," 2001 RELAP5 International Users Seminar, Sun Valley, ID, USA, September 5-7, http://www.inel.gov/relap5/rius/sunvalley/hiltbrandwilliams.pdf.

9. Judd, J., et al., 1996, "High-Fidelity, Real-Time Simulation with RELAP5/NESTLE," American Nuclear Society Winter Meeting, Washington, DC, USA, November 10-14.

10. Mesina, G., 2004, Visualization of RELAP5-3D Best Estimate Code, BE-2004, ANS Winter Meeting, Washington, D.C., November 14-18, http://www.inel.gov/relap5/products.htm.

11. Chow, H., P. Roth, and V. Ransom, 1985, "ATHENA Code Manual,” EGG-RST-7034, September.

12. Carlson, K., P. Roth, and V. Ransom, 1986, “ATHENA Code Manual,” EGG-RTH-7397, September. 
13. Meyer, C., R. McClintock, G. Silvestri, and R. Spencer, Jr., 1967, 1967 ASME Steam Tables--Thermodynamic and Transport Properties of Steam, The American Society of Mechanical Engineers, New York.

14. Moore, K., 1971, "ASTEM-A Collection of FORTRAN Subroutines to Evaluate the 1967 ASME Equations of State for Water/Steam and Derivatives of These Equations." ANCR-1026, October.

15. Wagner, R., 1977, "STH2O, A Subroutine Package to Compute the Thermodynamic Properties of Water," and "STH2X Water Property Subroutines," in: NRTS Environmental Subroutine Manual.

16. Schmidt, E., 1969, Properties of Water and Steam in SI Units, Springer-Verlag, New York.

17. Tolli, J., 1991, "Implementation of Heavy Water Thermodynamic and Transport Properties in RELAP5," EGG-EAST-9984, November.

18. Hill, P., et al., 1981, "Tables of Thermodynamic Properties of Heavy Water in S.I. Units," AECL 7531, December.

19. Hendricks, R., et al., 1973, "WASP - A Flexible FORTRAN IV Computer Code for Calculating Water and Steam Properties," NASA Technical Note D7391, November.

20. Aleman, S., et al., 1993, "FLOWTRAN-TF v1.2 Source Code," WSRC-TR-93, February.

21. Sicilian, J. and R. Harper, 1985, "Heavy Water Properties for the Transient Reactor Analysis Code (TRAC)," FSI-85-15-14-Q6-1, December.

22. Harr, L., J. Gallagher, and G. Kell, 1984, NBS/NRC Steam Tables: Thermodynamic and Transport Properties and Computer Programs for Vapor and Liquid States of Water in SI Units, Hemisphere, New York.

23. Harvey, A., A. Peskin, and S. Klein, 2000, "NIST/ASME Steam Properties," Version 2.2, Users' Guide, NIST Standard Reference Database, March.

24. Tolli, J., 1991, "Property Formulations for NonAqueous Fluids in ATHENA/MOD1," INEL Report, January.

25. Tolli, J. and A. Shieh, 1992, "Property Formulations for Ammonia in ATHENA/MOD1," INEL Report, June.
26. Reynolds, W., 1979, Thermodynamic Properties in S.I., Stanford University, Palo Alto.

27. Vargaftik, N., 1975, Tables on the Thermophysical Properties of Liquids and Gases, Hemisphere, Washington DC.

28. Weast, R., editor, 1973, Handbook of Chemistry and Physics, $54^{\text {th }}$ Edition, CRC Press, Cleveland.

29. Ward, L., 1995, "Application of RELAP5 to Medical Diagnostics and Modeling of the Cardiovascular System," Laboratory-Directed Research and Development Annual Report for FY 1994, INEL95/0270, June.

30. Daubert, T. and R. D. Danner, 1993, Physical and Thermodynamic Properties of Pure Chemicals, Taylor \& Frances, London.

31. Cooney, D., 1976, "Biomedical Engineering Principles," Marcel Dekker, New York.

32. Coryell, E. and C. Davis, 2002, "Implementation of Carbon Dioxide Thermodynamic and Transport Properties in ATHENA," INEEL Report R5/3D-0206, November.

33. McLinden, M., et al., 1999, "NIST Thermodynamic and Transport Properties of Refrigerants and Refrigerant Mixtures-REFPROP, Version 6.01 Users' Guide," U. S. Department of Commerce, NIST Standard Reference Database 23, July.

34. Hejzlar, P, 2002, Massachusetts Institute of Technology, personal communication, September.

35. Dostal, V., 2002, Massachusetts Institute of Technology, personal communication, October.

36. Vesovic, V., et al., 1990, "The Transport Properties of Carbon Dioxide," Journal of Physical Chemistry Reference Data," Volume 19, Number 3.

37. Daubert, T., et al., 1998, "Physical and Thermodynamic Properties of Pure Chemicals," DIPPR Project 801 Evaluated Process Design Data, AIChE and DIPPR Data.

38. Tolli, J., 1990, "Addition of Helium, Nitrogen, Sodium, and NaK to the RBIC Based ATHENA Program," INEL Report, March. 
39. Tolli, J., 1992, "Overview of Property Formulations for Helium, Nitrogen, Lithium, and Lithium-Lead in ATHENA/MOD1 with Comparisons of Calculated Properties to Measure Properties," INEL Report, April.

40. Shieh, A., 1999, "Addition of Lead-Bismuth as a Working Fluid in the ATHENA Code," INEEL Report, August.

41. Davis, C. and A. Shieh, 2000, "Overview of the Use of ATHENA Thermal-Hydraulic Analysis of Systems with Lead-Bismuth Coolant," $8^{\text {th }}$ International Conference on Nuclear Engineering, ICONE-8220, Baltimore, MD, USA, April 2-6.

42. Young, D., 1997, "A Soft Sphere Model of Liquid Metals," LLNL report UCRL-52352, November.

43. Hoover, W., 1975, "Generalized van der Waals Equation of State," Journal of Chemical Physics, Volume 63, Number 12, Page 5434.

44. Hultgren, R., et al., 1973, Selected Values of the Thermodynamic Elements, American Society for Metals, Metals Park, Ohio.

45. Kutateladze, S., et al., 1970, Liquid Metal Heat Transfer Media, Elsevier, Amsterdam.

46. Nesmeyanov, A., 1963, Vapor Pressure of the Chemical Elements, Elsevier, Amsterdam.

47. Touloukian, V., et al., 1970 Thermophysical Properties of Matter: Thermal Conductivity of Metallic Liquids, IFI/Plenum, New York.

48. Lyon, R., 1952, Liquid Metals Handbook, Office of Naval Research, US Department of Navy, Washington DC.

49. Tolli, J., 1989, "New Fluids Capability for the Thermal Hydraulic Analysis of Reactor Systems," INEL Report, November.

50. Blink, J., 1983, "Lithium Equation-of-State," LLNL report UCID-19890, September.

51. Maroni, V., et al., 1973, "A Review of the Chemical Physical, and Thermal Properties of Lithium that are Related to Its Use in Fusion Reactors," ANL report, March.
52. Smith, D., et al., 1984, "Blanket Comparison and Selection Study Final Report," ANL report, September.

53. Tolli, J., 1991, "Fluid Property Formulations for Nitrogen and Lithium-Lead as Used in ATHENA/MOD1,” INEL Report, March.

54. Angus, S., et al., editors, 1977, International Thermodynamic Tables of the Fluid State -6 , Nitrogen, Pergamon Press, Oxford.

55. National Bureau of Standards, 1981, Technical Note 1048.

56. Young, D., 1985, Lawrence Livermore National Laboratory, personal communication, December.

57. Young, D., 1989, Lawrence Livermore National Laboratory, personal communication, November.

58. Gierszewski, P., et al., 1980, "Property Correlations for Lithium, Sodium, Helium, Flibe, and Water in Fusion Reactor Applications," MIT report PFC-RR80-12, August.

59. Foust, O., editor, 1972, Sodium-NaK Engineering Handbook, Vol. 1, Gordon and Breach, New York.

60. Davis, C., 2005, "Implementation of Molten Salt Properties into RELAP5-3D/ATHENA," INEEL report INEEL/EXT-05-02658, January.

61. Sabharwall, P., et al., 2004, "Physical Properties and Correlations for the Molten Salt FLIBE [2Li-BeF2] and their Implementation in the RELAP5/ATHENA Thermal-Hydraulics Code," Oak Ridge National Laboratory, NSTD, August.

62. Powers, W., et al., 1963, "Physical Properties of Molten Reactor Fuels and Coolants," Nuclear Science and Engineering, Volume 17, pp. 200-211,

63. Cantor, S., et al., 1968, "Physical Properties of Molten-Salt Reactor Fuel, Coolant, and Flush Salts," ORNL report ORNL-TM-2316, August.

64. Cantor, S., 1973, "Density and Viscosity of Several Molten Fluoride Mixtures," ORNL report ORNL-TM4308, March.

65. Chase, W., 1998, NIST-JANAF Thermochemical Tables, $4^{\text {th }}$ Edition, Journal of Physical and Chemical Reference Data, Monograph No. 9. 
66. Knacke, O., et al., 1991, Thermochemical Properties of Inorganic Substances, $2^{\text {nd }}$ Edition, Springer-Verlag, Berlin.

67. Bird, R., W. Stewart, and E. Lightfoot, 1960, Transport Phenomena, Wiley, New York.

68. Williams, D., 2004, Oak Ridge National Laboratory, personal communication, October.

69. Tolli, J., 1993, “ATHENA MHD Model,” INEL report EGG-SC-93-107, February.

70. McCarthy, K., 1991, "MHD Section of ATHENA Code," INEL interoffice correspondence KAM-07-91, October.

71. McCarthy, K., 1992, "Information for Including MHD Section in ATHENA," INEL interoffice correspondence KAM-23-92, May.

72. Bayless, P., 2003, "VHTR Thermal-Hydraulic Scoping Analyses Using RELAP5-3D/ATHENA," Global 2003 Conference, ANS Winter Meeting, November 16-20.

73. Sabharwall, P., T. Marshall, and K. Weaver, 2005, "Temperature Effect on Heated Region Flow Starvation for Gas-Cooled Reactors," ANS Meeting, San Diego, CA, June 5-8.

74. Dostal, V., M. Driscoll, and P. Hejzlar, 2004, "A Supercritical Carbon Dioxide Cycle for Next Generation Nuclear Reactors," MIT-ANP-TR-100, March.

75. Fisher, J. and C. Davis, 2005, "RELAP5-3D Compressor Model," Space Nuclear Conference, ANS Meeting, San Diego, CA, June 5-8.

76. Merrill, B., "Application of ATHENA/RELAP5 to Fusion Loss-of-Cooling Accidents," 2000 RELAP5 International Users Seminar, Jackson Hole, WY, USA, September 12-14, http://www.inel.gov/relap5/rius/jackson/merrill.pdf. 